\title{
Utilização da Análise de Componentes Principais e do Método de Projeção de Galerkin para a Construção de Modelos de Ordem Reduzida
}

\section{Victor Zucatti da Silva*, William Roberto Wolf.}

\begin{abstract}
Resumo
Este trabalho aborda o estudo de métodos numéricos de ordem reduzida na resolução de equações diferenciais parciais da mecânica dos fluidos. O foco foi no método de projeção de Galerkin utilizando análise de componentes principais. Foram abordados os seguindos problemas: equação modelo de difusão, convecção, convecção-difusão e convecção não-linear. Os resultados obtidos apresentaram importantes reduções no custo computacional.
\end{abstract}

\section{Palavras-chave:}

Mecânica dos fluidos computacional, modelagem de ordem reduzida, projeção de Galerkin.

\section{Introdução}

O estudo de métodos computacionais e da mecânica dos fluidos é importante para a compreensão de uma grande quantidade de problemas do dia-a-dia. No entanto, as técnicas tradicionalmente utilizadas apresentam um custo elevado. O uso de métodos de ordem reduzida é uma forma de se reduzir o esforço computacional necessário à resolução aproximada de um problema sem grandes perdas de precisão.

O início do método é caracterizado pela análise e obtenção dos modos mais energéticos através da técnica de Análise de Componentes principais. Estes são posteriormente usados no método de projeção de Galerkin para otenção de um sistema dinâmicos descrevendo a física do sistema.

\section{Resultados e Discussão}

Os métodos foram implementados em Matlab na resolução dos problemas sugeridos por Coutinho (2014) devido a sua simplicidade inicial e interessante progressão de dificuldade.

Primeiramente, tratou-se a equação de convecção linear unidimensional devido a sua simplicidade. Fazendo a análise de componentes principais nota-se imediatamente que poucos são os modos necessários para representar quase a totalidade da energia do sistema e, portanto, obter um modelo de ordem reduzida drasticamente mais barato. A utilização de menos de $5 \%$ dos modos levou a construção de modos com um erro quadrático médio relativo inferior a $3 \%$.

O segundo problema a ser abordado foi a equação de convecção-difusão. Neste caso foi testado a capacidade de se obter um modelo reduzido com um coeficiente adimensional de valor intermediário a dois valores de simulações tradicionais. Os resultados foram novamente muito animadores.

O próximo passo foi a resolução de equação de convecção não-linear. A não-linearidade introduz um tensor de terceira ordem, logo a complexidade do problema aumenta em uma ordem de grandeza. Também foi observado a aparição do fenômeno de Gibbs na descontinuidade inerente ao problema. Apesar dessas penalizações o método se mostrou bastante superior aos métodos tradicionalmente utilizados. $\mathrm{Na}$ figura a seguir observa-se os resultados para a equação não-linear.
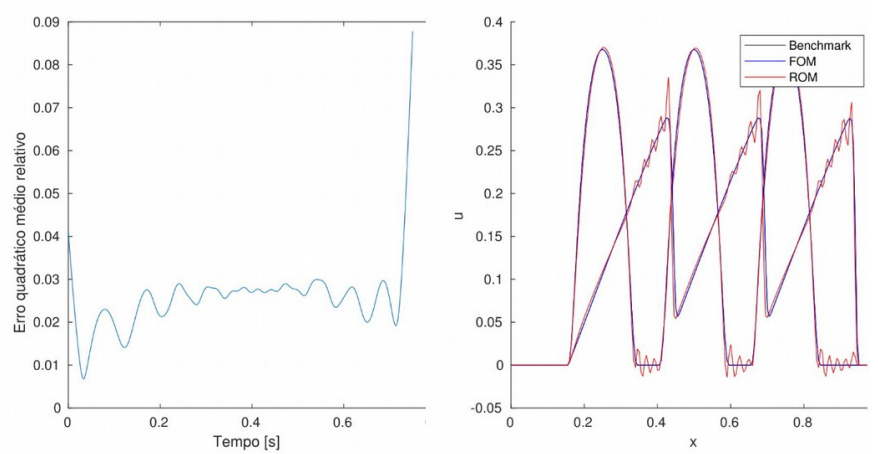

Figura 1. Erro quadrático médio relativo do modelo de ordem completa e do modelo de ordem reduzida (à esquerda) e comparação do padrão com modelo de ordem completa e do modelo de ordem reduzida com $\mathrm{m}$ = 21 modos espaciais (à direita).

Implementou-se uma técnica de diminuição do custo computacional de problemas não-lineares proposta por Dickson (2010). Esta ténica aprensentou resultados semelhantes à técnica tradicional.

\section{Conclusão}

Os resultados estão de acordo com a literatura e se mostram bastante promissores na obtenção de modelos computacionalmente mais baratos. No problema de convecção linear foi possível obter um modelo de ordem reduzida com uma velocidade qualquer desde que a condição inicial fosse a mesma da simulação de alta fidelidade. A equação de convecçãodifussão introduz um termo de natureza diferente. O problema de convecção não-linar apresentou resultados semelhantes ao caso linear e a técnica de grupo se mostrou promissora na modelagem deste tipo de problema ao reduzir a ordem de complexidade pela metade.

\section{Agradecimentos}

Ao programa CNPq/PIBIC pelo financiamento do projeto de pesquisa. Ao meu orientador William pelo apoio durante toda a execução do trabalho.

\footnotetext{
1 Silva, D. F. C.; Coutinho, A. L. G. A., Practical implementation aspects of Galerkin reduced order models based on proper orthogonal decomposition for computational fluid dynamics. J. B. S. Mech. Scie Eng. 2014.

2 Singler, J. R.; Dickson, B. T., Nonlinear model reduction using proper
} orthogonal decomposition, I. J. Num. Anal. Mod., 2010, V. 7, N. 2, 356-372. 